\title{
RESENHA
}

\section{REFLEXÕES SOBRE A GESTÃO DO CURRÍCULO}

\author{
REFLEXIONES SOBRE LA GESTIÓN DEL CURRICULUM
}

\section{REFLECTIONS ON CURRICULUM MANAGEMENT}

Iêda Braga Varges Lacerda

Universidade Estadual do Sudoeste da Bahia (UESB)

ROLDÃO, M. C. \& ALMEIDA, S. DE. Gestão curricular para a autonomia das Escolas e Professores. Lisboa: Ministério da Educação. Direção-Geral da Educação (DGE), 2018.

O livro Gestão curricular: Para a Autonomia das Escolas e Professores, escrito por Maria do Céu Roldão e Sílvia de Almeida, é fruto de uma adaptação da obra Gestão curricular: Fundamentos e práticas, escrita por Maria do Céu Roldão em 1999.

A obra é constituída pela introdução e mais três capítulos assim intitulados: Gestão curricular e trabalho docente (I), Gestão curricular como processo de tomada de decisão numa lógica de deliberação colaborativa (II) e Conceitos e ambiguidades (III).

$\mathrm{Na}$ Introdução, as autoras retomam as discussões sobre as políticas curriculares portuguesas acerca da autonomia curricular das escolas com a missão de trazer uma reflexão sobre a importância do currículo para a aprendizagem e sobre as mudanças já ocorridas desde a publicação da obra de Roldão, em 1999. São efetuadas críticas sobre a política de adição desenfreada de novos saberes ao currículo, mas de maneira "forçosamente simplificada" e "inviável" (p. 4), sendo esta uma proposta falha na produção de conhecimento real, tendo em vista que as disciplinas são formadas por tópicos sem conteúdo aprofundados.

No primeiro capítulo, Gestão curricular e trabalho docente, Roldão e Almeida dão as definições de gestão curricular e de currículo. As autoras apontam que muitas vezes o currículo

\begin{tabular}{|l|l|l|l|l|l|} 
Revista RBBA & ISSN 2316-1205 & Vitória da Conquista & V. 9 n ${ }^{\circ} 1$ & p. 386-389 & Julho/2020
\end{tabular}


é considerado como uma questão irrelevante por parte dos professores pelo fato de não terem consciência da função e do real significado deste.

As autoras destacam as mudanças que estão ocorrendo no currículo em Portugal e que elas ocorrem devido à pressão social para ajustar o currículo de acordo com diferentes necessidades, sejam "as necessidades sociais e económicas, os valores ou as ideologias sociais e educativas" (p. 7).

As autoras compreendem que o currículo deve ser elaborado de acordo com o meio social e temporal no qual a escola está inserida. Além disso, Roldão e Almeida discorrem sobre o papel da escola como mediadora e centro da decisão curricular. Elas defendem a autonomia das escolas na elaboração de seus próprios currículos a partir das bases nacionais, fazendo adequações necessárias para cada meio e público, visando à aprendizagem dos estudantes. Como resumo das mudanças que estão ocorrendo no currículo das escolas em Portugal, elas destacam alguns pontos importantes que resultam no insucesso escolar que muitas vezes é atribuído aos estudantes, como a ampliação do tempo escolar; o funcionamento arcaico, com turmas com grande número de estudantes sendo tratadas como homogêneas para otimizar custos; aplicação de planos organizativos e curriculares idênticos à situações completamente diferentes, etc.

A partir disso, as autoras apresentam a proposta de gestão curricular. Nessa proposta o currículo deve ser pensado como um binômio, sendo a base comum nacional o primeiro elemento e o segundo termo a autonomia das escolas na adaptação desses currículos de acordo com o meio em que ela está inserida.

No capítulo Gestão curricular como processo de tomada de decisão numa lógica de deliberação colaborativa, Roldão e Almeida (2018) trazem a gestão como tomada de decisões. Para as autoras, o processo de gerir é estruturado como: analisar, decidir, concretizar a decisão, avaliar o desenvolvimento e os resultados desta e, por fim, prosseguir, reorientar ou abandonar a decisão tomada.

Segundo as autoras, a decisão curricular é dividida em quatro níveis: central "que estabelece o currículo nacional"; institucional se refere a "adaptação do currículo nacional ao contexto das escolas"; grupal "se relaciona a adaptação do projeto curricular ao projeto de desenvolvimento curricular de cada turma" e individual que está "relacionado ao dia a dia da ação educativa", os quais articulam entre si no processo de tomada de decisões (p. 19-20). 
Deste modo, as decisões curriculares são divididas nos seguintes campos: visão pedagógica, as opções e prioridades, organização das aprendizagens, métodos e estratégias de ensino e avaliação, os modos de organização da escola e das aulas e por fim, a avaliação dos resultados das opções tomadas. E para a tomada dessas decisões há a necessidade de se distinguir os agentes dos parceiros, tendo em vista que o primeiro é o responsável pela assunção da decisão, enquanto que o segundo é o interveniente e interlocutor.

No último capítulo, intitulado Conceitos e ambiguidades, as autoras argumentam sobre a implementação do projeto de gestão curricular pelo qual a escola passa a ter a capacidade de escolher a maneira de trabalhar e gerir seus recursos tendo seu projeto educativo elaborado a partir da base nacional. Discorrem também sobre a formação para a gestão, tendo em vista que o modelo de gestão curricular discutido no livro é pouco conhecido e utilizado no meio educacional. Abordam ainda sobre a avaliação do processo, pois a qualidade das aprendizagens dos estudantes depende das decisões tomadas, e estas, são tidas como elemento central nesse processo avaliativo.

Além disso, as autoras também articulam sobre a contextualização e diferenciação dos currículos, pois é necessário diferenciar as propostas dos currículos de cada escola com o objetivo de melhor atender as características particulares de cada uma; e falam sobre disciplinas, interdisciplinaridade e articulação curricular, pois essa relação "visa a criação de espaços de trabalho conjunto e articulado em torno de metas educativas" (p. 42).

Roldão e Almeida finalizam o livro expressando suas visões acerca do papel e da capacidade das escolas de serem autônomas no desenvolvimento da gestão curricular abordada, visando o seu caminhar nas vias do sucesso, onde seus estudantes conseguem a aprendizagem necessária e proposta.

O livro traz uma proposta de gestão promissora ao abordar que as escolas devem ter autonomia para elaborar e gerir seus currículos tendo como referência uma base comum nacional. Assim, essa autonomia dada às escolas faz com que elas possam se autoavaliar e corrigir suas falhas, mantendo contínuo o processo de melhoramento da educação, e também tornando possível que todos os profissionais envolvidos possam assumir seus lugares nas tomadas de decisões sobre a gestão, uma vez que de acordo as autoras, o projeto curricular deve "ser de domínio das estruturas intermediárias de coordenação curricular e que devem permitir aos professores a realização conjunta de trabalho" (p.33). 
Outro ponto importante sobre a gestão curricular proposta é que ela vai contra a centralização da gestão curricular, largamente utilizada, pois muitas vezes este modelo de gestão faz com que a escola não diagnostique em tempo a presença de estudantes considerados como iletrados funcionais, que diante da sociedade atual, tem maiores chances de serem excluídos ou marginalizados, e assim, essas pessoas se afastam cada vez mais do conhecimento e da informação, sendo que estes são considerados como principal chave para a inclusão social.

O fato de a escola não diagnosticar os iletrados funcionais em tempo se dá ao fato de que o currículo é o meio de transporte que leva a aprendizagem pretendida ao estudante, sendo este veículo adaptado ao caminho a ser percorrido e ao seu destino final, mas que não é idealizado desta maneira na gestão centralizada, na qual o currículo é padronizado para caminhos e destinos diferentes e para públicos diferentes.

Escrito em linguagem acessível e conceituando as discussões propostas, a leitura desta obra é indicada para professores, coordenadores pedagógicos, diretores e todos os demais profissionais da educação básica, além de estudantes das licenciaturas e Pedagogia. , tendo em vista a constante mudança da sociedade, requerendo assim, mudanças na gestão curricular buscando a melhoria da qualidade educação.

\section{SOBRE A AUTORA}

Iêda Braga Varges Lacerda possui graduação em Licenciatura em Química pelo Instituto Federal de Educação, Ciência e Tecnologia da Bahia (IFBA). Atualmente é Mestranda em Ensino pelo Programa de Pós-Graduação em Ensino - PPGEN da Universidade Estadual do Sudoeste da Bahia (UESB).

Endereço eletrônico: iedavargeslacerda@gmail.com

ORCID: 0000-0003-4093-6404 